
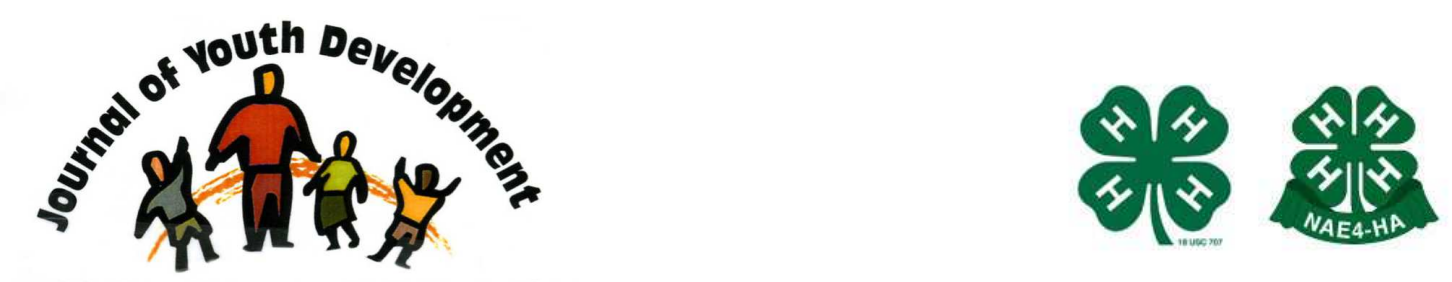

Bridging Research \& Practice

\title{
Dose: Comparison of 6 and 12 Nutrition and Physical Activity Sessions Targeting Middle School Adolescents
}

\author{
Mical Kay Shilts \\ Family \& Consumer Sciences \\ California State University Sacramento \\ Sacramento, CA \\ shiltsm@csus.edu \\ Anna C. Martin \\ Nutrition, Family \& Consumer Sciences \\ University of California Cooperative Extension \\ Stockton, CA \\ acmartin@ucdavis.edu \\ Marilyn S. Townsend \\ Nutrition Department \\ California State University Davis \\ Davis, CA \\ mstownsend@ucdavis.edu
}




\title{
JOURNAL OF YOUTH DEVELOPMENT \\ bridging research and practice

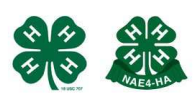

Volume 4, Number 4, Winter 2009

Article 090404FA004

\section{Dose: Comparison of 6 and 12 Nutrition and \\ Physical Activity Sessions Targeting Middle School Adolescents}

\author{
Mical Kay Shilts \\ California State University Sacramento \\ Anna C. Martin \\ University of California Cooperative Extension \\ Marilyn S. Townsend \\ University of California Davis
}

\begin{abstract}
Determining optimal intervention dose to meet time constraints of the teacher while maximizing behavioral impact for students has proven challenging. This study investigated the influence of intervention dose on 7th \& 8th grade participants' dietary and physical activity (PA) behaviors. Participants were assigned randomly to a: 1) 6 week-12 session nutrition intervention [treatment\#1], or 2) 3 week-6 session nutrition intervention [treatment\#2] with data collected pre/post intervention. Using ANCOVA, measures assessed dietary and PA self-efficacy and behaviors. Ethnically diverse participants $(n=107)$ were included in the analyses ( $46 \%$ male). All students set two goals: one dietary and one PA regardless of dose. Treatment\#1 resulted in similar outcomes compared to treatment\#2 with no significant differences between groups. As a result, we recommend that teachers using the 12 week intervention give students the option of setting new goals after the $6^{\text {th }}$ lesson to maintain motivation.
\end{abstract}

\section{Introduction}

Nutrition education interventions are generally implemented by classroom teachers who have limited time to introduce nutrition and fitness concepts to students. Determining optimal dosage of the intervention to maximize behavioral impact on students while meeting the time constraints of the teacher has proven to be a challenge. Dosage in the context of nutrition education has been defined by Olander (2007) as the amount of exposure to an intervention measured by number of lessons/contacts or length of time (i.e., school year).

We identified three dose related studies targeting youth. Assessment of the Know Your Body program indicated that those elementary school students receiving a higher intensity 
intervention had improved health measures (vegetable consumption, cholesterol, and systolic blood pressure) compared to students receiving lower intensity intervention (Resnicow, et al., 1992).

The School Health Evaluation Study found that peak knowledge, attitudes, and practice scores of students in grades 4-7 were obtained after approximately 50 hours of instruction (Connell, Turner, \& Manson, 1985). An evaluation of the Nutrition for Life program for inner-city junior high school students found that an increase in program intensity from two to five hours produced improved attitude and behavior scores (Devine, Olson, \& Frongillo, 1992). Lastly, among adult EFNEP participants in New York, the number of lessons completed was significantly associated with a greater reduction in food insecurity scores (Dollahite, Olsen, \& Scott-Pierce, 2003).

Although the results of these studies and logical thought support the common perception that increasing dosage generates improved outcomes, it is difficult to extrapolate specific intervention dosage recommendations from one intervention to another. Therefore, it would be advantageous to determine the optimal dosage for desired behavior outcomes for nutrition education programs while meeting the time constraints of school teachers.

The purpose of the study was to investigate the influence of intervention dose on participants' self-efficacy and behaviors for a nutrition and physical activity intervention targeting $7^{\text {th }}$ and $8^{\text {th }}$ grade students in California.

\section{Methods}

\section{Dosage}

Guidelines for California Expanded Food and Nutrition Education Program (EFNEP) (US Department of Agriculture Extension Service, October 1983) and Food Stamp Nutrition Education (FSNE) (US Department of Agriculture Food and Nutrition Service) specify a minimum of 6 hours of nutrition instruction for youth. Based on this information, we specified two dosages: 6-one hour sessions and 12-one hour sessions of classroom instruction.

\section{Design}

Students were assigned randomly to one of two treatment groups: 1) 6 week-12 session education intervention [treatment \#1], or 2) 3 week- 6 session education intervention [treatment \#2] with data collected before and after the intervention (Table 1). Students, but not the intervention educators, were blinded to the assignment. The first 6 sessions were taught by the same educator for both treatment groups in the same classroom. For sessions 712 , treatment \#1 and treatment \#2 participants were separated into different classrooms. Treatment \#1 participants received an additional 6 nutrition and physical activity education sessions followed by the posttest. Treatment \#2 participants received the posttest, then 6 sessions of a money management curriculum followed by another posttest. 
Table 1

Intervention Schedule

\begin{tabular}{|c|c|c|}
\hline Week & Treatment \# 1 & Treatment \# 2 \\
\hline \multirow{2}{*}{1} & \multicolumn{2}{|c|}{ Consent Forms } \\
\hline & \multicolumn{2}{|c|}{ Pretest } \\
\hline \multirow{2}{*}{2} & \multicolumn{2}{|c|}{ Nutrition and fitness basics } \\
\hline & \multicolumn{2}{|c|}{ Diet analysis and goal setting } \\
\hline \multirow{2}{*}{3} & \multicolumn{2}{|c|}{ Fitness analysis and goal setting } \\
\hline & \multicolumn{2}{|c|}{ Heart rate and energy balance } \\
\hline \multirow{2}{*}{4} & \multicolumn{2}{|c|}{ Food label activity } \\
\hline & \multicolumn{2}{|c|}{ Breakfast importance } \\
\hline \multirow[t]{2}{*}{5} & $\begin{array}{l}\text { Food preparation and tasting } \\
\text { (fruit pizza) }\end{array}$ & $\begin{array}{l}\text { Posttest } \\
\text { Money management video }\end{array}$ \\
\hline & $\begin{array}{l}\text { Fitness fundamentals and } \\
\text { goal setting }\end{array}$ & Money personality activity \\
\hline \multirow[t]{2}{*}{6} & $\begin{array}{l}\text { Food preparation and tasting } \\
\text { (sweet potato chips) and } \\
\text { dietary fat activity }\end{array}$ & Savings account information \\
\hline & Fast food activity & Shopping savvy \\
\hline \multirow{2}{*}{7} & Media savvy skills & Checking account information \\
\hline & $\begin{array}{l}\text { Personal goal collage and } \\
\text { media activity }\end{array}$ & E banking information \\
\hline \multirow[b]{2}{*}{8} & Posttest & Posttest \\
\hline & Celebration & Celebration \\
\hline
\end{tabular}

Teaching the intervention were community nutrition educators for California Food Stamp Nutrition Education (FSNE, now named Supplemental Nutrition Assistance Program--Education) who were trained and certified to teach the subject. The study protocol was approved by the Institutional Review Board at the University of California, Davis.

\section{Intervention}

EatFit, based on the Social Cognitive Theory (Bandura, 1986), was designed to improve the dietary and physical activity behaviors of middle school students (Horowitz, Shilts, \& Townsend, 2004). Goal setting instruction was the primary focus of the intervention. Students set one dietary and one physical activity goal using the guided goal setting procedure described elsewhere (Horowitz, Shilts, \& Townsend, 2005; Shilts, Townsend, \& Horowitz, 2004) and shown to be effective in promoting adolescent behavior change (Shilts, Horowitz, \& Townsend, 2009). This procedure provides participants with choices from a collection of practitionerdeveloped major and minor goals containing attributes necessary for optimal goal effectiveness: specificity, proximity, difficulty, and attainability (Locke \& Lantham, 1990; Shilts, Horowitz, \& Townsend, 2004; Shilts, Horowitz, \& Townsend, 2009). A key element in this strategy is that the adolescent selects his or her own goal. A complete list of the major and minor goal options is available from the first author. 
Variables known to influence behavior were specifically used throughout the intervention (selfmonitoring, barriers counseling, goal-setting, skills mastery, cue management, contracting, modeling, social support, reinforcement, cognitive restructuring, and relapse prevention) (Bandura, 1986). This intervention was designed specifically for three U.S. Department of Agriculture youth programs in California: EFNEP, FSNE and 4- $\mathrm{H}$. This National 4-H juried curriculum has been reported previously (Horowitz, Shilts, \& Townsend, 2004; Shilts, Horowitz, \& Townsend, 2009).

The alternate curriculum, Money Talks: Should I be Listening? for sessions 7-12 for treatment \#2 participants contained no nutrition or physical activity content. Ordering information for EatFit and Money Talks are available at http://anrcatalog.ucdavis.edu.

\section{Sample}

A convenience sample was drawn from a low-income, urban middle school in central California. The participants were $7^{\text {th }}$ and $8^{\text {th }}$ grade students $(n=157)$ from all five periods of the home economics course taught at this middle school. The middle school had $65 \%$ enrollment in free/reduced price meals and met criteria for participation in two US Department of Agriculture nutrition education programs for low-income youth, EFNEP and FSNE.

\section{Measures}

Content. A self-administered instrument assessed participants' dietary behaviors (19 items), physical activity behaviors ( 4 items), dietary self-efficacy (19 items), physical activity selfefficacy (4 items), and goal commitment (2 items). Behavior and self-efficacy items addressed the specific targeted behaviors of the intervention. Self-efficacy was defined as confidence to perform a targeted behavior. Goal commitment questions were included to ascertain both treatment groups' dedication to the goal set.

Response range for the behavior-related items was an 8-point scale signifying the number of days per week the participant engaged in the targeted behavior, i.e., 0-7 days per week. The response range for the self-efficacy items was a 4-point scale, i.e., 1, not at all sure, to 4, being totally sure.

The items in the dietary and physical activity behavior sections were adapted from the Centers for Disease Control Youth Risk Behavior Survey (YRBS). The YRBS dietary and physical activity items were modified slightly to include specific targeted behaviors of the intervention.

Reliability testing of YRBS items with a nationally representative sample of adolescents indicated Kappas ranging from 91.1-64.2\% (Brener, Collins, Kann, Warren, \& Williams, 1995).

Cognitive and Reliability Testing. Using the concurrent method of Willis (1994), all items adapted for this study were assessed using cognitive interviewing techniques as recommended by Contento, et al (Contento, et al., 2002).

In individual interviews with 8th grade students $(n=16)$, items were cognitively tested using four questions: What does the question mean to you using your own words? How did you come up with your answer? Thinking about other students in your grade at school, would any of these words be difficult for them? How would you make this question clearer to them? Items were evaluated for content validity by three experts in behavioral nutrition and found to represent the construct domain. The revised instrument was then pilot tested with 6-8th graders $(n=34)$ (Shilts, Townsend, \& Horowitz, 2002). 
A reliability assessment of the revised instrument was conducted to establish that the items were measuring phenomena in a reproducible and consistent way (Carmines \& Zeller, 1979; Litwin, 1995). Seventh and 8th grade students $(n=46)$ completed the instrument on two occasions, three weeks apart, with no intervention. Reliability coefficients were .73 for the dietary behavior items, .55 for the physical activity behavior items, .59 for dietary self-efficacy items and .48 for physical activity self-efficacy items. Scales and instruments used with adults are thought to have good test retest reliability with coefficients of .7 or greater (Litwin, 1995; Shilts, Lamp, Horowitz, \& Townsend, 2009). The coefficients for the dietary behavior items met this criterion. The other coefficients are lower than .7 indicating more random error associated with the items (Townsend, Sylva, Martin, Metz, \& Wooten-Swanson, 2008). Because the reliability assessments were conducted with 12-14 year olds, we are considering them marginally acceptable for our purposes.

\section{Analysis}

Statistical analyses were conducted using SAS PC version 8.1.(SAS Institute Inc.) Double data entry in two separate files was performed and each file was compared for differences using the compare procedure. Differences were compared within groups using paired t-test and between groups using a chi square test. For analyses using analysis of covariance, the explanatory variable was group (12 session EatFit intervention [treatment group \#1], or 6 session EatFit intervention [treatment group \#2]) as the main effect with covariates being pre-intervention score, gender, class period, and ethnicity. The response variables were dietary self-efficacy, physical activity self-efficacy, dietary behavior, and physical activity behavior.

\section{Results}

\section{Participants}

Before commencing the intervention, participants $(n=157)$ were randomly assigned to one of two treatments groups. Of the 157 potential, 31 participants did not return both consent and assent forms by the end of the 8-week intervention period, nine did not complete the evaluation instruments and 10 attended fewer than 10 of the 12 EatFit sessions (treatment \#1) or fewer than 4 of the 6 EatFit sessions (treatment \#2). The attrition rates were similar for both treatment groups for return rate of consent forms and completion of evaluation instruments. However, more participants in treatment \#1 $(n=12)$ did not complete the required number of sessions ( $>10)$ compared to treatment \#2 (>4, n=4, p =.02). Therefore, 107 participants (46 treatment \#1 and 61 treatment \#2), with an average age of $12.2 \pm 0.6$ years were included in the analyses. More than half (54\%) of the participants were female. Participants selfreported as Hispanic (39\%), Asian/Pacific Islander (27\%), non-Hispanic white (15\%), nonHispanic black (8\%), mixed ethnicity (8\%) and American Indian (2\%). No significant difference between treatment \#1 and treatment \#2 groups were found for gender, age or ethnicity using chi square tests.

Between $44 \%$ and $63 \%$ of treatment \#1 participants showed improvement in dietary and/or physical activity self-efficacy and behaviors while $31 \%$ to $46 \%$ of treatment \#2 participants made positive improvements (Figure 1). Chi square tests revealed no significant differences between groups. 
Figure 1

Percent of Treatment \#1 and Treatment \#2 Participants Who Improved Dietary and Physical Activity Self-Efficacy and Behaviors $(n=107)$

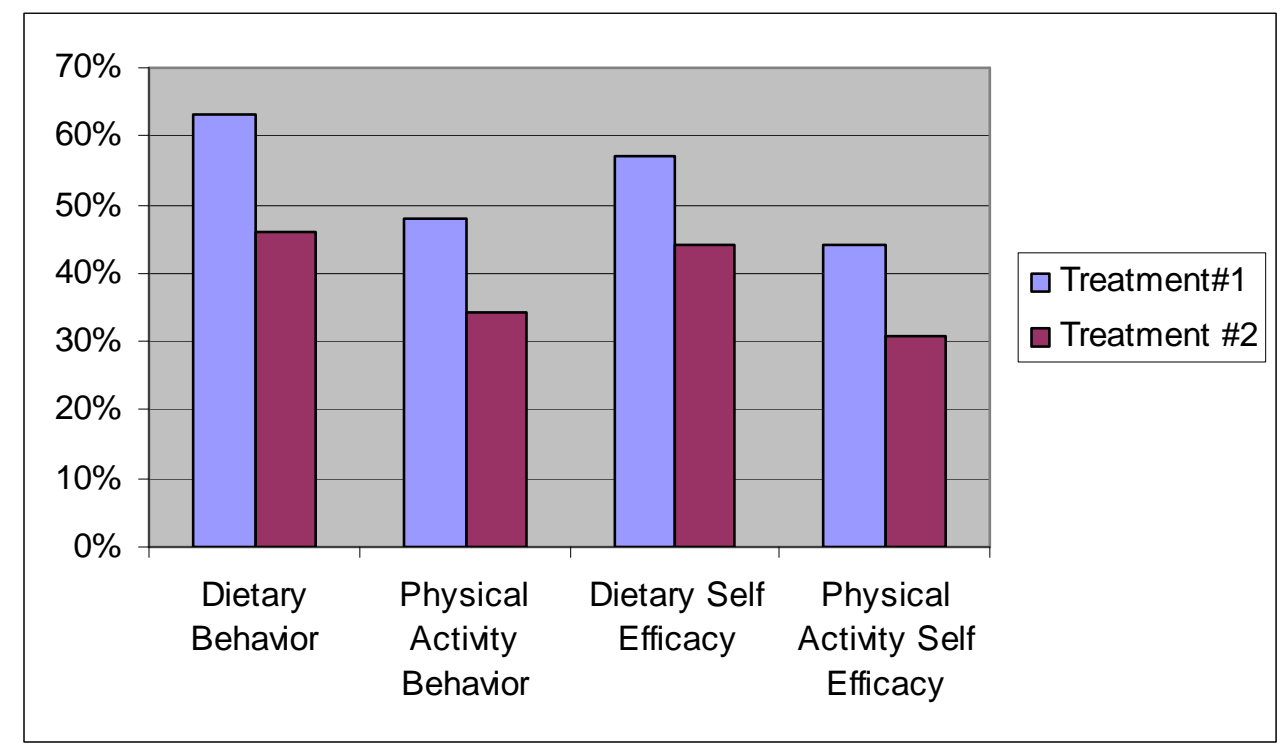

Participants were asked on the posttest if they made an effort to reach their eating and physical activity goals. Most participants reported they made an effort to reach their eating goal (treatment $\# 1=91 \%$, treatment $\# 2=87 \%$ ) and their physical activity goal (treatment $\# 1=$ $93 \%$, treatment \#2 = 87\%). Chi square test revealed no differences between groups for the eating $(p=.11)$ or physical activity $(p=.13)$ goal effort.

Participants' mean scores for the four outcome variables for pre and post tests were compared using a paired t tests. Treatment \#1 participants made significant improvements in dietary behaviors $(p=.02)$, but did not make any other significant improvements in dietary and physical activity self-efficacy or physical activity behavior. Treatment \#2 participants did not make any significant improvements from pretest to posttest in dietary and physical activity self-efficacy or behaviors.

Using analysis of covariance, the explanatory variable was group (treatment \#1 or treatment \#2) as the main effect with covariates being pre-intervention score, gender, class period, and ethnicity. The response variables were change in dietary self-efficacy, physical activity selfefficacy, dietary behavior, and physical activity behavior. No significant differences were found between treatment groups for the dietary behavior $(p=.12)$, dietary self-efficacy $(p=.22)$, physical activity behavior $(p=.21)$, or physical activity self-efficacy $(p=.19)$ variables (Table 2$)$. 
Table 2

Change Scores for Treatment \#1 and Treatment \#2 Participants

by Outcome Variable* $(n=107)$

\begin{tabular}{|l|l|l|l|}
\hline Variable & $\begin{array}{l}\text { Treatment \# 1 } \\
\mathbf{1 2} \text { EatFit sessions+ } \\
\text { (n=46) } \\
\text { Mean } \pm \text { SD }\end{array}$ & $\begin{array}{l}\text { Treatment \# 2 } \\
\text { 6 EatFit sessions+ } \\
\text { (n=61) } \\
\text { Mean } \pm \text { SD }\end{array}$ & p value \\
\hline Dietary Behavior & $4.85 \pm 13.67$ & $1.30 \pm 14.50$ & 0.12 \\
\hline Dietary Self-Efficacy & $-0.63 \pm 8.46$ & $1.08 \pm 9.94$ & 0.22 \\
\hline Physical Activity and Behavior & $0.37 \pm 7.68$ & $-0.52 \pm 4.49$ & 0.21 \\
\hline Physical Activity Self- Efficacy & $-0.57 \pm 2.58$ & $0.39 \pm 3.00$ & 0.19 \\
\hline $\begin{array}{l}\text { *Model controlled for pretest score, gender, ethnicity, and class period } \\
+ \text { Unadjusted means and standard deviations reported }\end{array}$ \\
\hline
\end{tabular}

\section{Discussion}

The delivery of a 12-session intervention did not result in greater improvement in dietary and physical activity self-efficacy and behavior compared to a smaller dosage of 6-sessions.

A possible explanation for no difference in the physical activity behavior variable was that participants in both groups scored high on the pretest with an average score of 19.41 out of a possible 28. This may have been a factor in the non-significant differences between groups.

An unexpected reduction in self-efficacy in the treatment \#1 group was found. This was not matched by the treatment \# 2 group which showed no change in self-efficacy. Participants in both groups could have had unrealistically high expectations for their capabilities prior to the intervention as noted on the pre-test for both groups. Similar findings about self-efficacy have been reported in previous research for fruit, vegetable, and fat intake (Bogers, Brug, Assema, \& Dagnelie, 2004; Brug, Assema, Kok, Lenderink, \& Glanz, 1994). After the longer intervention period (12 sessions), participants may have been more realistic about their capabilities compared to the participants receiving 6 sessions (Shilts, Smith, Ontai, \& Townsend, 2008). This may confound comparisons of change in self-efficacy using a traditional pre/post measure (Howard et al., 1979). Traditional pre/post format has been noted to contain "optimistic bias", also known as "response shift bias", a possible cause of internal invalidity of the assessment tool (Rohs, Langone, \& Coleman, 2001). There is some evidence to suggest that administering the self-efficacy measure retrospectively may provide a more accurate reflection of change in confidence (Howard et al., 1979; Pratt, McGuigan, \& Katzeva, 2001; Shilts et al., 2008).

In a comparison to other studies, we find that Nutrition for Life (Devine et al., 1992) and the California Youth EFNEP Evaluation Study (Townsend, Johns, Shilts, \& Farfan-Ramirez, 2006) are similar to this study in that all three have relatively short interventions of 5 to 12 hours of instruction time. In contrast, Know Your Body (Resnicow et al., 1992) and the School Health Evaluation Study (Connell et al., 1985) are intensive with 50 hours minimum devoted to instruction. Our study differs from these three in that our design included randomization at the child level with a small sample size. The three studies randomized at the classroom level and reached over 1,800 children each. 


\section{Limitations}

Two major limitations should be discussed. These limitations are sufficiently critical to account for the findings of no difference between the two dosages. First, both consent and assent forms were not returned for 32 children participating in the study. Although the attrition rates were not different for the two groups, the individual dropouts may have differentially influenced the outcomes (Campbell \& Stanley, 1966).

Second, our physical activity behavior measure may have low power, i.e., a limited ability to detect change. We do not have the psychometric analysis detecting the ability of the tool to detect change following the intervention, i.e. sensitivity to change (Townsend \& Kaiser, 2007). The low reliability coefficient most certainly indicated sizable amounts of random error associated with the tool (Townsend et al., 2008).

\section{Conclusion}

Because our study found no difference between the 6 and 12 session interventions, we did not find the optimal dosage. We know six sessions was insufficient to produce behavior change. Instead integrating a segment of nutrition education into each quarter of the school year should be tested. For future research, a larger disparity in intervention dosage may be needed to detect a difference between groups as well as the use of more sensitive and reliable instruments. In addition, we recommend reevaluating treatment \#1 (12 sessions), but this time giving students the option of setting new goals after the 6th lesson to maintain motivation for behavior change.

\section{Acknowledgements}

We wish to thank California Food Stamp Nutrition Education (FSNE) for funding this study. We also wish to thank Christine Davidson, Jan Peerson, the San Joaquin County Youth FSNE staff Joyce Bishop, Larissa Leavens, and Gricelda Ocegueda, and Mrs. Suzi Post and her students for helping the study come to fruition.

\section{References}

Bandura, A. (1986). Foundations of Thought and Action: A Social Cognitive Theory. Englewood Cliffs, NJ: Prentice-Hall.

Bogers, R., Brug, J., Assema, P.V., \& Dagnelie, P. (2004). Explaining fruit and vegetable consumption: the theory of planned behavior and misconception of personal intake levels. Appetite, 42, 157-166.

Brener, N.D., Collins, J.L., Kann, L., Warren, C.W., \& Williams, B.I. (1995). Reliability of the Youth Risk Behavior Survey questionnaire. Amer J Epidemiol, 141(6), 575-580.

Brug, J., Assema, P.V., Kok, G., Lenderink, T., \& Glanz, K. (1994). Self-rated dietary fat intake: associations with objective assessment of fat, psychosocial factors, and intention to change. Journal Nutrition Education, 26(5), 218-223.

Campbell, D.T., \& Stanley, J.C. (1966). Experimental and Quasi-experimental Designs for Research. Chicago: Rand McNally. 
Carmines, E., \& Zeller, R. (1979). Reliability and Validity Assessment. Newbury Park, CA: Sage Publications.

Connell, D., Turner, R., \& Manson, E. (1985). Summary of findings of the School Health Education Evaluation: Health promotion effectiveness, implementation and costs. Journal of School Health, 55, 316-321.

Contento, I.R., Randell, J.S., \& Basch, C.E. (2002). Review and analysis of evaluation measures used in nutrition education intervention research. JNEB, 34(1), 2-25.

Devine, C.M., Olson, C.M., \& Frongillo, E.A. (1992). Impact of the Nutrition for Life program on junior high students in New York State. Journal of School Health, 62(8), 381-385.

Dollahite, J., Olsen, C., \& Scott-Pierce, M. (2003). The impact of nutrition education on food insecurity among low-income participants in EFENP. Family and Consumer Sciences Research Journal, 32(2), 127-139.

Horowitz, M., Shilts, M.K., \& Townsend, M.S. (2004). EatFit: a goal oriented intervention that challenges middle school adolescents to improve their eating and fitness choices. Journal of Nutrition Education and Behavior, 36(1), 43-44.

Horowitz, M., Shilts, M.K., \& Townsend, M.S. (2005). Adapting a diet analysis program for an adolescent audience. Journal of Nutrition Education and Behavior, 37, 43-44.

Howard, G.S., Ralph, K.M., Gulanich, N.A., Maxwell, S.E., Nance, D., \& Gerber, S.L. (1979). Internal invalidity in pretest-posttest self-report evaluations and the re-evaluation of retrospective pretests. Applied Psychological Measurement, 3, 1623.

Litwin, M. (1995). How to Measure Survey Reliability and Validity. Thousand Oaks, CA: Sage Publications.

Locke, E.A., \& Lantham, G.P. (1990). A Theory of Goal Setting and Performance. Englewood Cliffs, NJ: Prentice-Hall.

Olander, C. (2007). Nutrition Education and the Role of Dosage: Office of Analysis, Nutrition and Evaluation. Food and Nutrition Service, USDA.

Pratt, C., McGuigan, W., \& Katzeva, A. (2001). Measuring program outcomes: using retrospective pretest methodology. Am J Eval, 21, 341-349.

Resnicow, K., Cohn, L., Reinhardt, J., Cross, D., Reinhardt, J., Futterman, R., et al. (1992). A three-year evaluation of the Know Your Body Program in inner-city schoolchildren. Health Educ Q, 19(4), 463-480.

Rohs, F.R., Langone, C.A., \& Coleman, R.K. (2001). Response shift bias: a problem in evaluating nutrition training using self-report measures. Journal of Nutrition Education and Behavior, 33(3), 165-170.

SAS Institute Inc. (Version 8.1). Cary, NC. 
Shilts, M.K., Lamp, C., Horowitz, M., \& Townsend, M.S. (2009). Pilot study: EatFit impacts $6^{\text {th }}$ graders' academic performance on achievement of math and English education standards. Journal of Nutrition Education and Behavior. 41(2), 127-131)

Shilts, M.K., Horowitz, M., \& Townsend, M.S. (2004). Goal setting as a strategy for dietary and physical activity behavior change: a review. American Journal of Health Promotion, 19(2), 8193.

Shilts, M.K., Horowitz, M., \& Townsend, M.S. (2009). Guided Goal Setting: Effectiveness in a dietary and physical activity intervention with low-income adolescents. International Journal of Adolescent Medicine and Health, 20(1), 111-122.

Shilts, M.K., Smith, D., Ontai, L., \& Townsend, M.S. (2008). Evidence to support the use of the retrospective pretest method to measure dietary and physical activity behavior and self-efficacy in adolescents. Journal of Youth Development, 3(1), \#080301RS080002.

Shilts, M.K., Townsend, M.S., \& Horowitz, M. (2002). Pilot study of the EatFit intervention to determine sample size and protocol for a randomized controlled trial (pp. Available at:

http://socialmarketing-nutrition.ucdavis.edu/publications.htm\#review6. Accessed June 28, 2006: Center for Advanced Studies in Nutrition and Social Marketing, University of California, Davis.

Shilts, M.K., Townsend, M.S., \& Horowitz, M. (2004). An innovative approach to goal setting for adolescents: guided goal setting. Journal of Nutrition Education and Behavior, 36(3), 155-156.

Townsend, M.S., Johns, M., Shilts, M.K., \& Farfan-Ramirez, L. (2006). Evaluation of a USDA nutrition education program for low-income youth. Journal of Nutrition Education and Behavior, $38(1), 30-41$.

Townsend, M.S., \& Kaiser, L. (2007). Brief psychosocial fruit and vegetable tool is sensitive for United States Department of Agriculture's nutrition education program. Journal of the American Dietetics Association, 107, 2120-2124.

Townsend, M.S., Sylva, K., Martin, A., Metz, D., \& WJooten-Swanson, P. (2008). Improving readability of an evaluation tool for low-income clients using visual information processing theories. Journal of Nutrition Education and Behavior, 40, 181-186.

US Department of Agriculture Extension Service. (October 1983). EFNEP, Expanded food and nutrition education program. Retrieved December 2, 2008, from http://www.crees.usda.gov/nea/food/efnep/pdf/program-policy.pdf

US Department of Agriculture Food and Nutrition Service. Food stamp nutrition education guiding principles. Retrieved December 1, 2008, from http:www.fns.usda.gov/oane/menu/FSNE/GuidingPrinciples.pdf

Willis, G. (1994). Cognitive Interviewing and Questionnaire Design: A Training Manual (Working Paper Series No. 7). Hyattsville, MD: Centers for Disease Control and Prevention, National Center for Health Statistics.

(C) Copyright of Journal of Youth Development Bridging Research and Practice. Content may not be copied or emailed to multiple sites or posted to a listserv without copyright holder's express written permission. However, users may print, download or email articles for individual use. 